Article type: full paper

\title{
Tuning the wicking and wettability properties of PET textiles by DBD or a remote atmospheric $\mathrm{RF}$ torch : a comparison
}

\author{
Annaëlle Demaude ${ }^{1 *}$, Rosanna Inturri ${ }^{2}$, Cristina Satriano $^{3}$, Perrine Leroy ${ }^{4}$, and François \\ Reniers ${ }^{1}$
}

${ }^{1}$ Université libre de Bruxelles, Faculty of Sciences, Analytical and Interfacial Chemistry, cp 255, Avenue F.D. Roosevelt 50, B-1050 Bruxelles, Belgium

${ }^{2}$ Fidia Farmaceutici S.p.A., R\&D Unità locale Fidia Research sud, Contrada Pizzuta - 96017 Noto (SR), Italy

${ }^{3}$ University of Catania, Department of Chemical Sciences, NanoHybrid BioInterfaces Lab (NHBIL), V.le Andrea Doria 6, 95125 Catania, Italy

${ }^{4}$ IONICS Surface Technologies, Plasma Department, Rue René Descartes 1, B-7000 Mons, Belgium

*Correspondence

Annaëlle Demaude, Université libre de Bruxelles, Faculty of Sciences, Analytical and Interfacial Chemistry, cp 255, Avenue F.D. Roosevelt 50, B-1050 Bruxelles, Belgium Email: ademaude@ulb.ac.be

Textile industry is constantly searching for easy and rapid ways to improve the properties of textiles. In this matter, plasma treatments have already proven to be an efficient and green solution, as they proceed in dry environment and require minimal use of chemicals. To date, most of the work on the subject has been performed with low-pressure plasmas. Recently, the 
atmospheric plasmas have been the focus of an increased interest, in particular for industrial applications. Indeed, the possibility to avoid the use of pumping systems makes this technology easily implementable in continuous in-line processes. For many applications, the treatment aims at modifying the textile surface in order to increase the overall hydrophilicity. The latter is often probed by water contact angle, but this do not always reflect the global hydrophilic behavior of the textile as a 3D-material. A complementary study of the wicking properties is important to better reflect the penetration of liquids into the textile but is poorly reported in the literature. The present work aims at increasing the water uptake of PET textile by direct or remote plasma treatment, which are the two main trends in this field. For this purpose, a dielectric barrier discharge (DBD) and a RF plasma torch at atmospheric pressure are used, respectively. Different plasma parameters are varied and their respective effect on the wicking properties of the fabric, assessed by an absorbency test developed ad hoc, are correlated to their surface chemical composition determined by X-ray photoelectron spectroscopy (XPS). These results are compared with the possible changes in wetting of the fibers surface witnessed by water contact angles measured on PET foil samples submitted to the same plasma treatments. A complete wicking of water in PET textile can be obtained after $20 \mathrm{~s}$ or $10 \mathrm{~s}$ of torch treatment with pure Ar plasma or $\mathrm{Ar} / \mathrm{O}_{2}$ mixture, respectively. On the other hand, a comparable effect is detected, after $30 \mathrm{~s}$ of DBD Ar plasma treatment, at the used experimental conditions, whereas the addition of $\mathrm{O}_{2}$ to the discharge have the opposite effect on the fabric wicking. These results are discussed in terms of the peculiar processes in surface activation and modification of the fabric surface triggered by the two different plasma technologies.

Keywords: Atmospheric plasma; poly(ethylene terephthalate) (PET) fabric; wettability; wicking; X-ray photoelectron spectroscopy 
Abbreviations: APPJ, atmospheric pressure plasma jet; PET, polyethylene terephthalate;

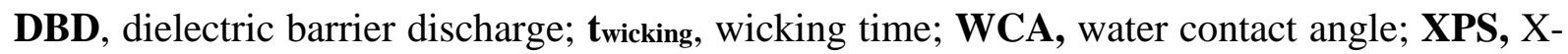
ray photoelectron spectroscopy

\section{INTRODUCTION}

Fabrics made from polyester fibers exhibit several attractive properties, including good elasticity, shape retention, wrinkle resistance, excellent wash-and-wear performance and robustness, which make these materials widely used in all kinds of apparel fabrics. Other than in the clothing industry, polyester textiles may also find many applications in the biomedical field (such as gowns, respiratory masks, gauzes for wound dressing, etc.). ${ }^{[1,2]}$ In particular, polyester fabrics made from poly(ethylene terephthalate) (PET) are attractive for their high uniformity, strength, and good durability. Indeed, they represent almost $50 \%$ of all fiber materials. ${ }^{[3-5]}$ However, most PET textiles are highly hydrophobic and can display a significant amount of surface static charges, inducing discomfort in wear and making these fibers difficult to dye, coat, or clean. ${ }^{[6,7]}$ While fabrication strategies of superhydrophobic textiles for constructing fabric surfaces with anti-wetting property can be exploited to obtain surfaces with demonstrated self-cleaning, self-healing, UV-blocking, photocatalytic, and anti-bacterial performances, the opposite approach, i.e., increasing the textiles hydrophilicity is generally desired to improve their water uptake, but also their adhesion to other materials. ${ }^{[8]}$ Regarding this matter, alkaline soda processes have been traditionally used over years by textile industries, but generated environmental issues because of the high consumption of chemicals, water and energy in the final drying step. ${ }^{[9-11]}$ Pasquet et al. have shown that plasma treatments are environmental friendly alternatives to wet chemical hydrophilization of polyester fabrics. ${ }^{[12]}$

Since their early exploitation in material sciences in the 1960 s, low pressure plasmas have been used more and more frequently to modify the properties of textiles. Depending on the 
plasma parameters, including the nature of the gas, the discharge power or the exposure time, different reactive functional groups can be grafted on the surface of the fibers and the etching of the latter can be observed as well. ${ }^{[13-16]}$ That way, the fabric surface free energy can be modified quite simply, with the possibility to tune the respective weight of polar (Lewis acidbase) and dispersive (Lifshitz van der Waals) components of the plasma-modified PET surfaces. ${ }^{[17]}$

However, low-pressure plasmas can be difficult to use in the context of industrial scale applications. Their pumping systems consume a lot of energy and often limit their use to batch mode. Noteworthy, atmospheric plasmas can be generated in open perimeter mode, which allow them to be implemented in in-line continuous processing. In recent years, atmospheric plasmas have grown increasing attention but work still needs to be done to achieve a complete understanding and control of the reaction mechanisms involved in their interaction with textile surfaces.

Leroux et al. demonstrated that air-plasma treatments performed with a dielectric barrier discharge (DBD) increase the wettability of PET textile, due to surface oxidation processes. ${ }^{[18]}$ Specifically, the authors investigated several PET fabrics at different structure porosity, concluding that the porosity plays an important role on the level of surface oxidation and on the amount of PET chain scissions at the fiber surface during the plasma treatment. In another work by the same team, some restructuring of PET along with its degradation during air-plasma treatments was evidenced. ${ }^{[19]}$ The restructuring depended on the applied power and the speed of sample displacement in the discharge; they also showed that an optimal treatment both inside and at the surface of the fabric could be obtained by controlling these two parameters.

Kan and Yuen were able to improve the wettability properties of polyester and polyamide woven fabrics using an atmospheric pressure plasma jet (APPJ) with $\mathrm{He}$ and $\mathrm{O}_{2}$ as carrier and reactive gas, respectively. ${ }^{[20]}$ They also found out that oxygen containing hydrophilic groups had been introduced into the fabric after plasma treatments. 
The present paper reports on the increase of PET textile hydrophilicity by means of two different atmospheric plasma devices, namely a dielectric barrier discharge (DBD) and a RF plasma torch both operating with Ar as main gas. In each case, different plasma parameters were varied, and the effects of the resulting plasma treatments on the textile were investigated. The progression of the hydrophilic properties of the PET fabric was followed with a water absorbency test developed ad hoc (see experimental section). Moreover, water contact angle (WCA) measurements were performed on PET foil samples exposed to the same plasma treatments as a comparison of their effects on a "flat" nonporous PET material. X-ray photoelectron spectroscopy (XPS) analyses were carried out to shed light on the relationship between the wettability change of the treated fabric and their surface average composition and structure.

\section{EXPERIMENTAL SECTION}

\subsection{Materials}

PET bilayer woven fabric was produced by SEFAR ${ }^{\circledR}$ MEDITEX ACC and provided by Fidia Farmaceutici S.p.A. (Italy). $1 \mathrm{~mm}$ thick PET foils were purchased from Eriks NV (Belgium). The plasma gases used were $99.99 \%$ pure argon - alphagaz 1, 99.99\% pure oxygen - alphagaz 1, and 99.7\% pure carbone dioxide - N27, all from Air Liquide.

\subsection{Plasma treatments}

2.2.1 Atmospheric dielectric barrier discharge (DBD)

The atmospheric DBD system used in this work was a rolling stage system, depicted in Figure 1. An electronic control panel allowed the displacement of the lower electrode (an 18.5 
$\mathrm{x} 100 \mathrm{~cm}$ aluminum plate) along the powered upper electrodes (two $6.5 \times 17.5 \mathrm{~cm}$ copper plates) at a controlled speed. Top and bottom electrodes were covered by a $5 \mathrm{~mm}$ and $4 \mathrm{~mm}$ thick borosilicate glass plates respectively, acting as dielectric. The sample was deposited on the lower electrode and carried inside the $5 \mathrm{~mm}$ wide discharge gap at a speed of $11 \mathrm{~mm} \mathrm{~s}^{-1}$ for 5 , $10,20,30$ or $75 \mathrm{~s}$. The discharge was fed by a $15 \mathrm{~L} \mathrm{~min}^{-1}$ argon flow with or without the addition of $0.01,0.05,0.1$ or $0.2 \mathrm{~L} \mathrm{~min}^{-1}$ of $\mathrm{O}_{2}$ using flowmeters through a slit between the upper electrodes, and powered at 40,60 , or $80 \mathrm{~W}$, at a frequency of $17.14 \mathrm{kHz}$.

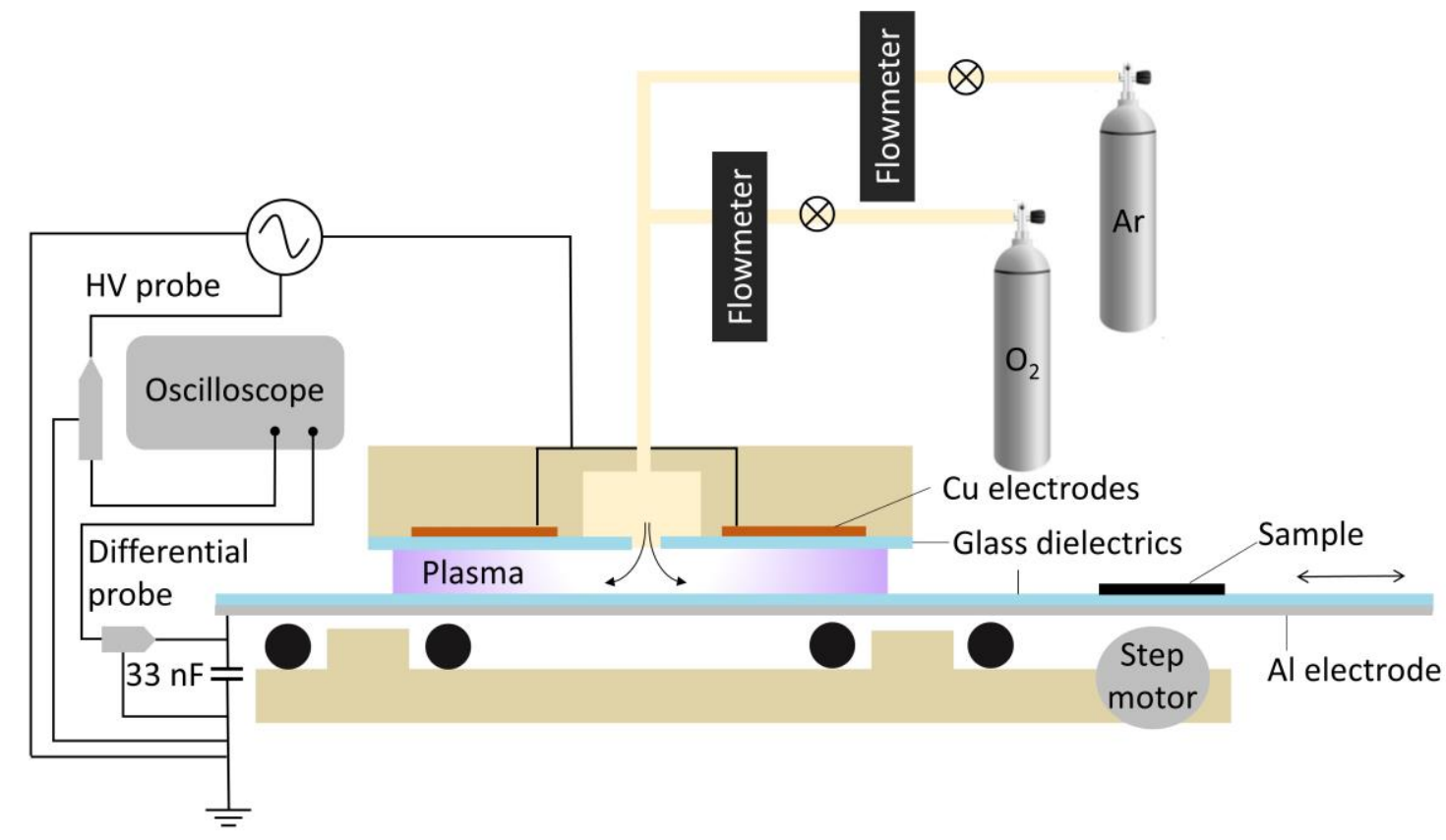

FIGURE 1. Scheme of the DBD reactor ${ }^{[21,22]}$

The power absorbed by the plasma was measured using Lissajous method. A high voltage probe and a $33 \mathrm{nF}$ capacitor were connected to the power supply and in series to the bottom electrode, respectively. The voltage applied to the DBD and the voltage across the capacitor, from which the current can be deduced, were recorded on an oscilloscope. From these data, the Energy (in Joule) for one cycle (area inside the Lissajous curve) can be calculated and multiplied by the frequency (in $\mathrm{s}^{-1}$ ) to obtain the Power discharge (in Watt).

\subsubsection{Atmospheric RF plasma torch}


The RF plasma torch used in this work was an Atomflo ${ }^{\circledR} 400$ from SurfX Technologies LLC (see Figure 2). The instrument was equipped with an Atomflo 400 Controller, and an AH-250D plasma torch applicator (60 $\mathrm{mm}$ diameter x $160 \mathrm{~mm}$ length circular deposition head), providing an active area of $25 \mathrm{~mm}$ of inner diameter. The torch was operated at $60 \mathrm{~W}$ with $30 \mathrm{~L} \mathrm{~min}^{-1}$ of argon with or without the addition of $0.01 \mathrm{~L} \mathrm{~min}^{-1}$ of $\mathrm{O}_{2}$ or $\mathrm{CO}_{2}$ gases. The samples were treated 3 or $6 \mathrm{~mm}$ away from the head of the torch, for 10,15 or $20 \mathrm{~s}$.
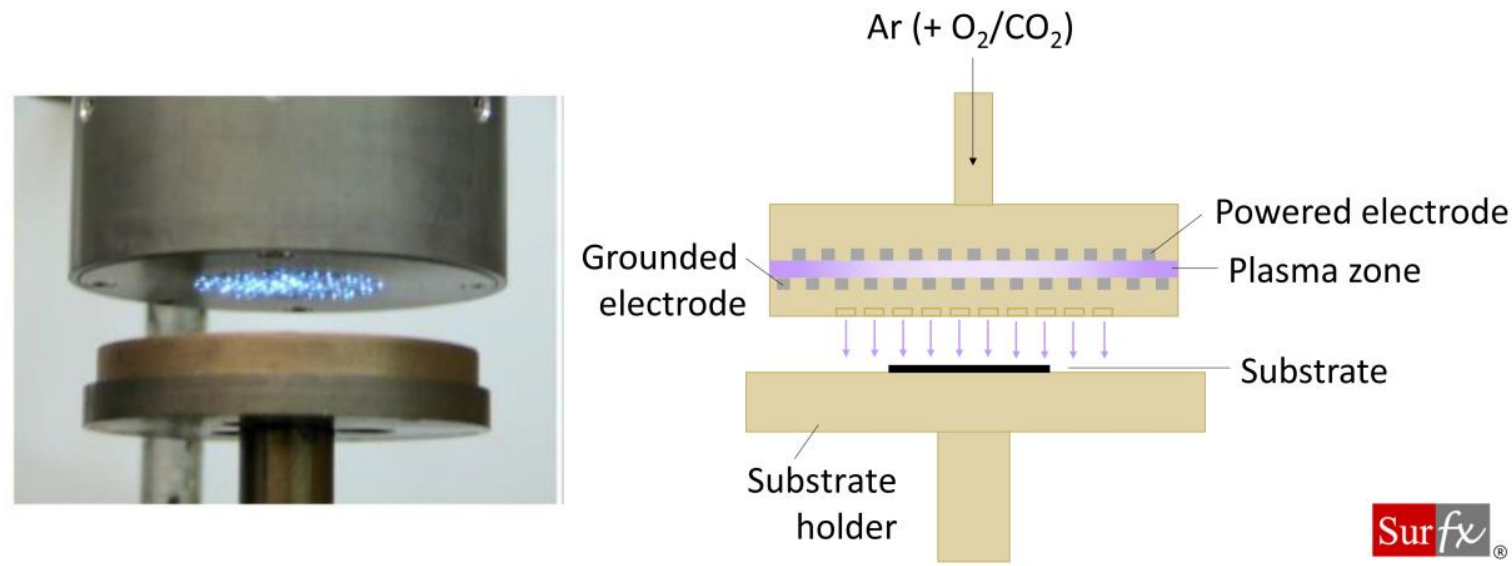

FIGURE 2. Photograph and scheme of the plasma torch reactor

\subsection{Methods}

\subsubsection{Sample preparation}

The PET fabric was cut into single layer pieces of dimensions $1.0 \times 1.5 \mathrm{~cm}^{2}$. After plasma treatments, each piece of fabric was taped onto thin glass coverslips to prevent the textile from creasing for further characterizations. The PET foil was cut into $2 \times 2 \mathrm{~cm}^{2}$ samples and cleaned with methanol prior to plasma treatments.

\subsubsection{Water contact angle (WCA) measurements}


The WCA measurements on the PET foil samples were performed immediately after plasma treatment using a Krüss DSA100 goniometer (static mode) and Drop Shape Analysis software. For each plasma condition, at least 3 treated samples were characterized by deposition of a 3 $\mu \mathrm{L}$ de-ionized water droplets at $400 \mu \mathrm{L} \mathrm{m^{-1 }}$ dispensing rate (5 droplets per sample). Hence, the WCA values were calculated as the average ( \pm standard deviation) of all measurements recorded for all 3 samples.

\subsubsection{Absorbency test}

The method developed in this work to evaluate the wicking properties of the PET fabric samples consisted in measuring the time it takes for water to wick into the textile based on video recordings. After the delivery of a $3 \mu \mathrm{L}$ de-ionized water droplet on the textile surface by the automated syringe system of a DSA 100 goniometer, the progression of the drop absorbency was recorded by the goniometer camera with a 25 -fps recording speed and a 768 x 576 frame resolution. Observation of the recorded frames, as shown in Figure 3 for a plasma-treated PET fabric sample, allowed to precisely determine the moment when it can be considered that the water has wicked into the fabric. This moment was arbitrarily fixed at the reappearance of the textile texture through the remaining surface water. The wicking time, $t_{\text {wicking, }}$, is thus defined by Equation 1 as the elapsed time, in seconds less than 60, from the moment the drop reaches the surface $t_{A}$ (Figure 3, sequence A) to the moment where the fabric texture underneath the drop begins to show again, $t_{C}$ (transition from sequence B to C in Figure 3, and first appearance of fabric texture circled in red in Figure 4):

$$
t_{\text {wicking }}=t_{C}-t_{A}
$$

The shorter the wicking time, the more absorbent the fabric. 


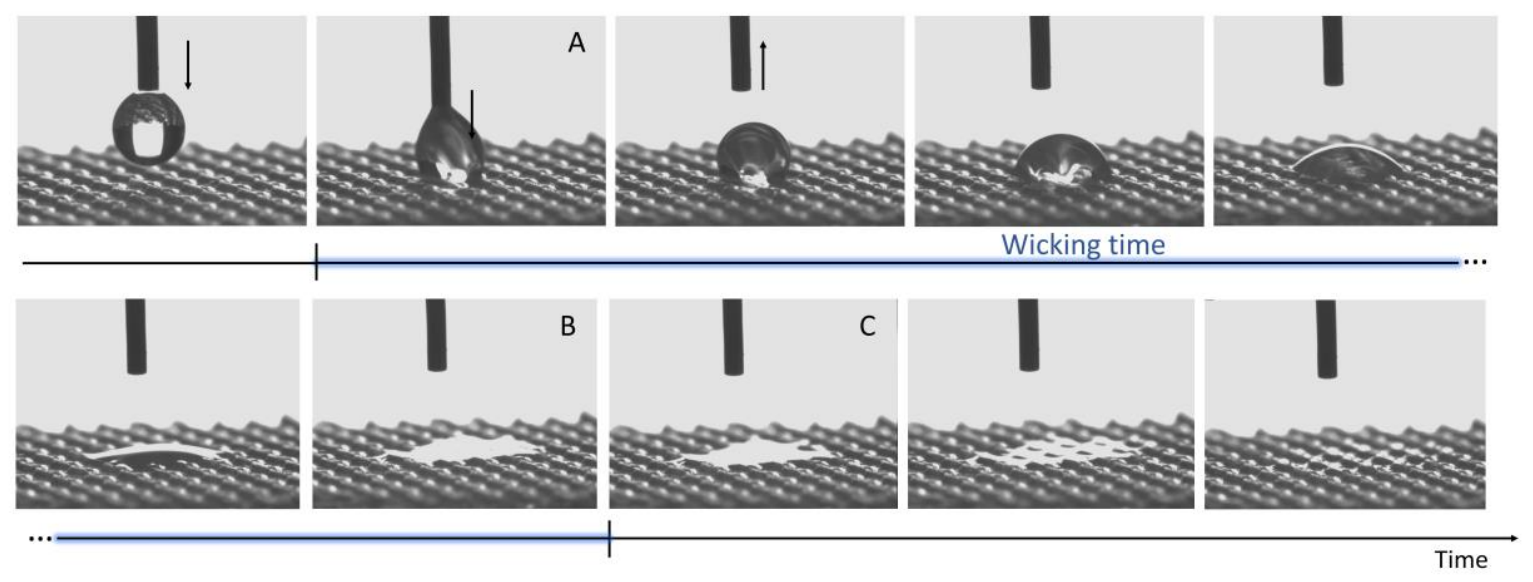

FIGURE 3. Determination of wicking time, based on the camera recording of a $3 \mu \mathrm{L}$ de-ionized water droplet deposition and absorption by a plasma treated PET fabric sample (DBD treatment for $10 \mathrm{~s}$, at $40 \mathrm{~W}$ and $17.14 \mathrm{kHz}$, with $15 \mathrm{~L} \mathrm{~min}^{-1}$ of argon). The wicking time is determined as the elapsed time from sequence A to sequence $\mathrm{C}$.

Choosing $t_{C}$ time as the end point of $t_{\text {wicking }}$ measurement enables our method to be quite reproducible. Indeed, in the frames as presented in Figure 4, the texture of the fabric appears relatively contrasted with the reflection of light by water, which makes $t_{C}$ easier to spot than, for example, the moment the drop completely disappears in the textile fibers.

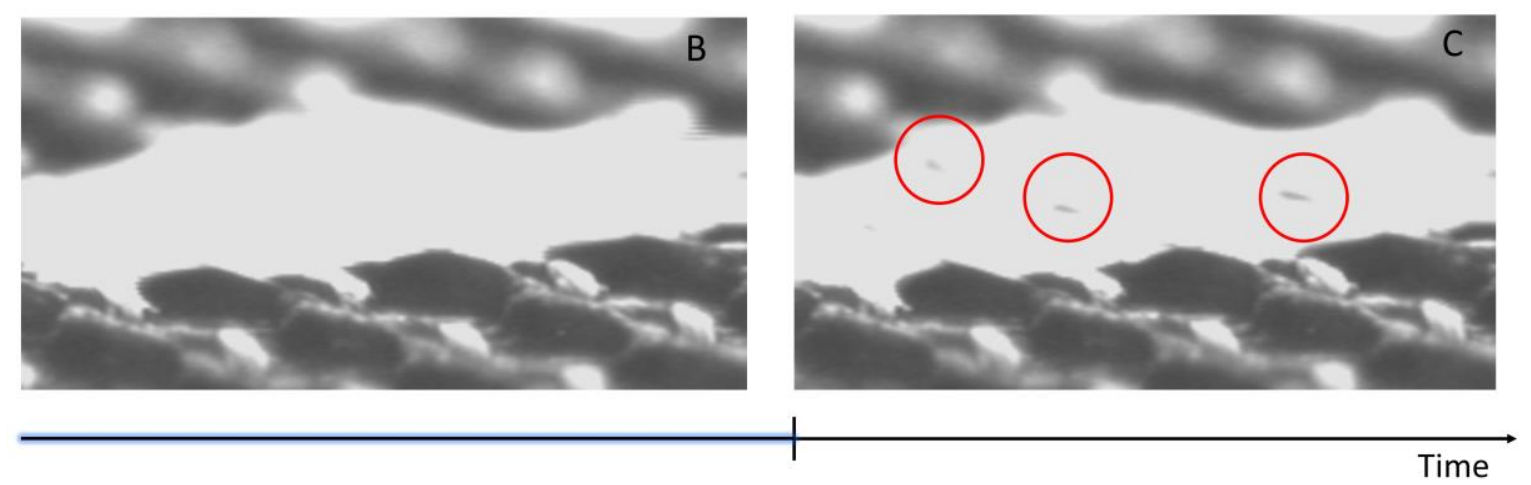

FIGURE 4. Close picture of sequences $\mathrm{B}$ and $\mathrm{C}$. The first apparition of the fabric texture through the water is visible in sequence $C$, in the red circles.

A similar absorbency method is reported by the American Association of Textile Chemists and Colorists (AATCC): the Test Method 79-2007, Absorbency of Textiles (also called "areal wicking test"). ${ }^{[23]}$ This test consists in measuring the time required for the specular reflection 
of a water drop deposited on the textile surface to disappear. In other words, it is the time for the water drop to no longer reflect light and appear only as a dull wet spot. The fabric specimen is mounted on an embroidery hoop prior to the test to ensure a taut wrinkle-free surface, and the water drop is delivered by a burette fixed at a determined height from the textile surface. The measurement is based on the naked eye observation of the operator, which uses a stopwatch to record the wicking time. Their method thus differs slightly from ours in the way to flatten the fabric and in the water drop delivery system, but more importantly on the procedure to determine the wicking time. Ours offers the possibility to analyze closely the behavior of the drop thanks to the video recordings and to give a precise definition of the wicking time.

For each plasma conditions, $t_{\text {wicking }}$ is the average of all measurements taken on 3 different samples ( 2 drops per sample) immediately after plasma treatment. As in the AATCC Test Method 79-2007, when the drop disappears immediately, the wicking time is recorded as "zero", and when the wicking time exceeds $60 \mathrm{~s}$, it is recorded as "60+ s".

\subsubsection{X-ray photoelectron spectroscopy (XPS) characterization}

Surface atomic composition of PET fabric samples was determined by XPS analysis using a PHI 5600 Physical Electronics photoelectron spectrometer. The source of the analyzer was an $\mathrm{Al}$ anode powered at $250 \mathrm{~W}$ with pass energies of 190 and $24 \mathrm{eV}$ for survey and highresolution scans, respectively. CasaXPS software was used for the determination of average surface concentrations, with $\mathrm{C} 1 \mathrm{~s}$ and $\mathrm{O} 1 \mathrm{~s}$ sensitivity factors of 0.205 and 0.63 , respectively, as well as for the deconvolution of the C1s spectral envelope, fitted with a standard GaussianLorentzian, and a Shirley background.

\section{RESULTS AND DISCUSSION}


The different plasma parameters tested in this work for the torch and DBD treatments of PET materials are reported in Table $\mathbf{1 .}$

TABLE 1. Plasma parameters tested for the treatment of the PET fabric and the model PET foil by DBD and RF plasma torch. Primary gas: Ar (15 L min-1 in the case of the DBD, and $30 \mathrm{~L} \mathrm{~min}-1$ in the case of the torch), DBD frequency: $17140 \mathrm{~Hz}$.

\begin{tabular}{|c|c|c|c|c|c|}
\hline Parameters & $\begin{array}{c}\text { Secondary } \\
\text { gas }\end{array}$ & 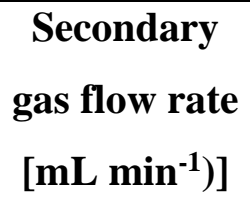 & $\begin{array}{c}\text { Exposure } \\
\text { time } \\
{[\mathrm{s}]}\end{array}$ & $\begin{array}{c}\text { Applied } \\
\text { power } \\
{[W]}\end{array}$ & $\begin{array}{c}\text { Sample-torch } \\
\text { distance } \\
{[\mathrm{mm}]}\end{array}$ \\
\hline RF Torch & $\mathrm{O}_{2}, \mathrm{CO}_{2}$ & 10 & $10,15,20$ & 60 & 3,6 \\
\hline DBD & $\mathrm{O}_{2}$ & $\begin{array}{c}10,50, \\
100,200\end{array}$ & $\begin{array}{c}5,10,20,30 \\
75\end{array}$ & $40,60,80$ & l \\
\hline
\end{tabular}

When evaluating the wettability of textile surfaces, WCA determination is often the central technique. Although it is well suited to assess the wettability of polymeric surface such as coating films, it is less obvious to apply it in the case of textile materials. Indeed, their heterogeneous structure and the suction effect caused by their porosity on the drop strongly affect the contact angle determination. ${ }^{[24]}$ Moreover, WCA only provide information about the wetting of the fabric top surface, which is not always enough to describe all the hydrophilic properties of textiles. Indeed, wicking is also an important feature to consider and can be assessed by different absorbency tests (capillary rise, areal wicking, etc.). ${ }^{[13,25,26]}$ Even though they are closely related, Kissa and Harnett insisted on the importance to distinguish wetting from wicking when addressing the wettability properties of textiles. ${ }^{[24,27]}$ Wetting can be defined as the displacement of an air-fiber interface with a liquid-fiber interface and is completely determined by the chemical nature of the fibers and their geometry (in particular their roughness), whereas wicking is the spontaneous absorption of liquid in the fibers, driven by capillary force and is affected by the way the fibers are arranged into the fabric. Therefore, 
the results of the absorbency test also give information about the wetting state of the textile surface, as wetting of the fabric is a prerequisite for wicking.

Nonetheless, WCA measurements were performed on "model" PET foil samples submitted to the same plasma treatments than the PET fabric samples. Even though the resulting WCA values obtained on the foils do not directly represent the wettability of the corresponding treated fibers, these model samples were used to witness the possible modification of surface wetting of PET by the different plasma treatments. Indeed, Leroux et al. evidenced that the amount of energy received from the plasma per surface area depends on the roughness and structure porosity of the surface. ${ }^{[18]}$ The "model" PET surface would be more altered than the PET fabric surface by a same plasma discharge.

\subsection{PET fabric treated by atmospheric plasma torch}

Figure 5 shows the measured wicking time and the water contact angle for PET fabric and model PET foil samples, before and after the surface treatment with the RF torch, respectively.

From Figure 5a, it appears that the bare untreated PET fabric is quite hydrophobic, with a recorded $t_{\text {wicking }}$ exceeding $60 \mathrm{~s}$ (“60+ $\mathrm{s}$ "). After $10 \mathrm{~s}$ of pure Ar torch treatment, the water wets more the surface and begin to wick into the fabric. When adding either $\mathrm{O}_{2}$ or $\mathrm{CO}_{2}$ as a secondary gas to the discharge, the water absorption becomes instantaneous ("0 s"). 

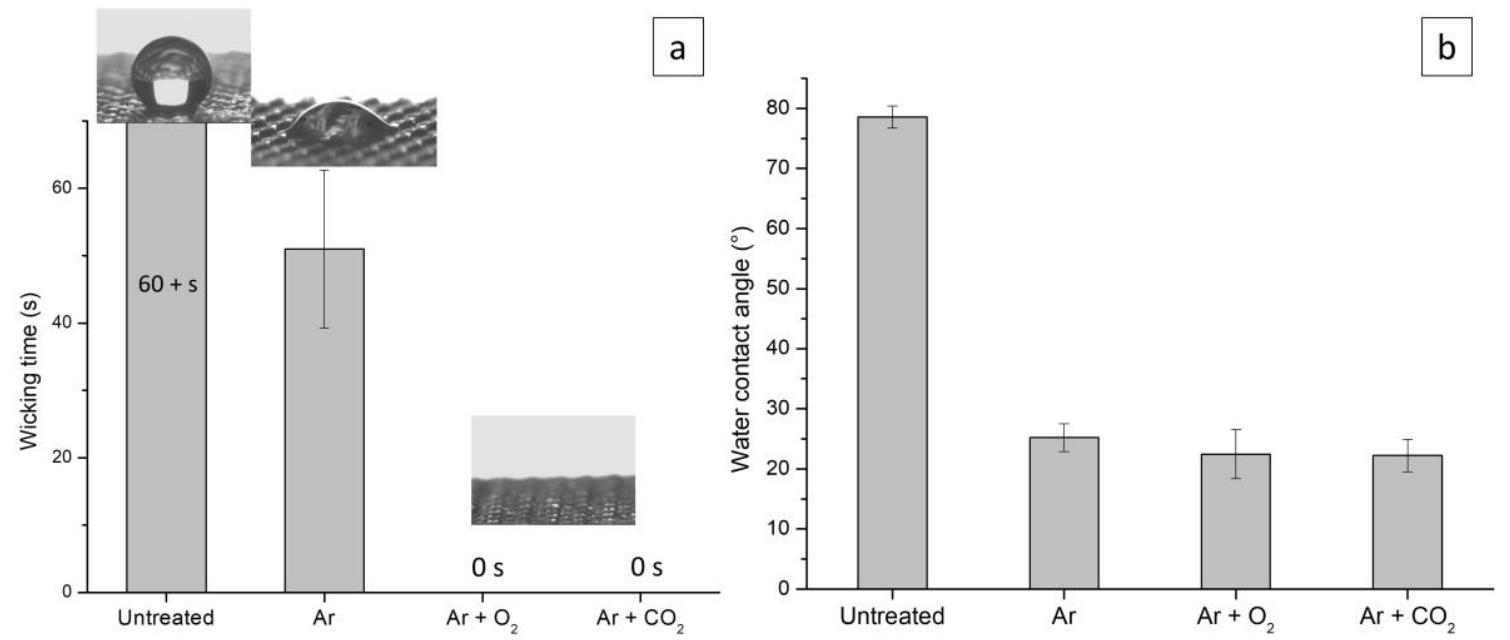

FIGURE 5. Wicking time of untreated and RF torch plasma-treated PET fabric with the corresponding picture of the drop 1s after it has reached the surface (a) and water contact angle of untreated and RF torch plasma-treated model PET foil samples (b). Torch operating parameters are: $30 \mathrm{~L} \mathrm{~min}^{-1}$ of Ar as the primary gas (with and without addition of $0.01 \mathrm{~L} \mathrm{~min}^{-1}$ of $\mathrm{O}_{2}$ or $\mathrm{CO}_{2}$ as secondary gas), $60 \mathrm{~W}$ of applied power, a distance of $6 \mathrm{~mm}$ from the head of the torch to the samples surface, and a treatment duration of $10 \mathrm{~s}$.

The WCA measured on the model PET samples submitted to the same torch treatments are reported in Figure 5b. Standard deviation of the measurements on a same treated sample were comprised within those of the bare PET surface, suggesting good surface homogeneity of the treatment performed. A significant decrease of WCA can be noticed between the untreated samples $\left(\sim 78^{\circ}\right)$ and those treated with pure $\operatorname{Ar}\left(\sim 25^{\circ}\right)$. A slight further decrease of WCA is also observed when adding one of the secondary gases. However, no big difference was noted between the samples treated either with $\mathrm{Ar} / \mathrm{O}_{2}$ or $\mathrm{Ar} / \mathrm{CO}_{2}$ mixture.

The improvement of the treated fabric samples wicking could thus be due to the modification of the surface chemistry and/or roughness caused by the Ar torch treatment and emphasized by the addition of $\mathrm{O}_{2}$ or $\mathrm{CO}_{2}$ in the discharge.

Figure 6 shows the results of XPS analyses for the PET fabric samples untreated and exposed to the different torch treatments. The $\mathrm{O} / \mathrm{C}$ ratios (fig. $6 \mathrm{c}$ ) calculated from the $\mathrm{O} 1 \mathrm{~s}$ and $\mathrm{C} 1 \mathrm{~s}$ peaks area clearly indicate the incorporation of oxygen to the textile surface with Ar torch 
treatment, and slightly greater with the addition of $\mathrm{O}_{2}$ or $\mathrm{CO}_{2}$ to the discharge. Fittings of the $\mathrm{C} 1 \mathrm{~s}$ envelope displayed in Figure $6 \mathrm{c}$ revealed that this increase of oxygen can be attributed to the introduction of $\mathrm{C}-\mathrm{O}, \mathrm{C}=\mathrm{O}$ and $\mathrm{O}-\mathrm{C}=\mathrm{O}$ species such as carbonyl, carboxyl or hydroxyl functional groups, which can improve surface wettability.

Similar studies conducted on the effects of Ar post-discharge (atmospheric pressure plasma jet, APPJ) treatments of PET films or fibers also conclude that the increase of the polymer hydrophilicity is mainly due to the grafting of oxygen containing polar groups or chain scission processes and possibly by the generation of some surface roughness. ${ }^{[28-31]}$ Although activation mechanisms of polymer by plasmas at low pressure are different, Tkavc et al. also found no significant difference between the treatment of PET with either $\mathrm{O}_{2}$ or $\mathrm{CO}_{2}$ low pressure plasma in terms of changes in surface chemistry. ${ }^{[32]}$ 


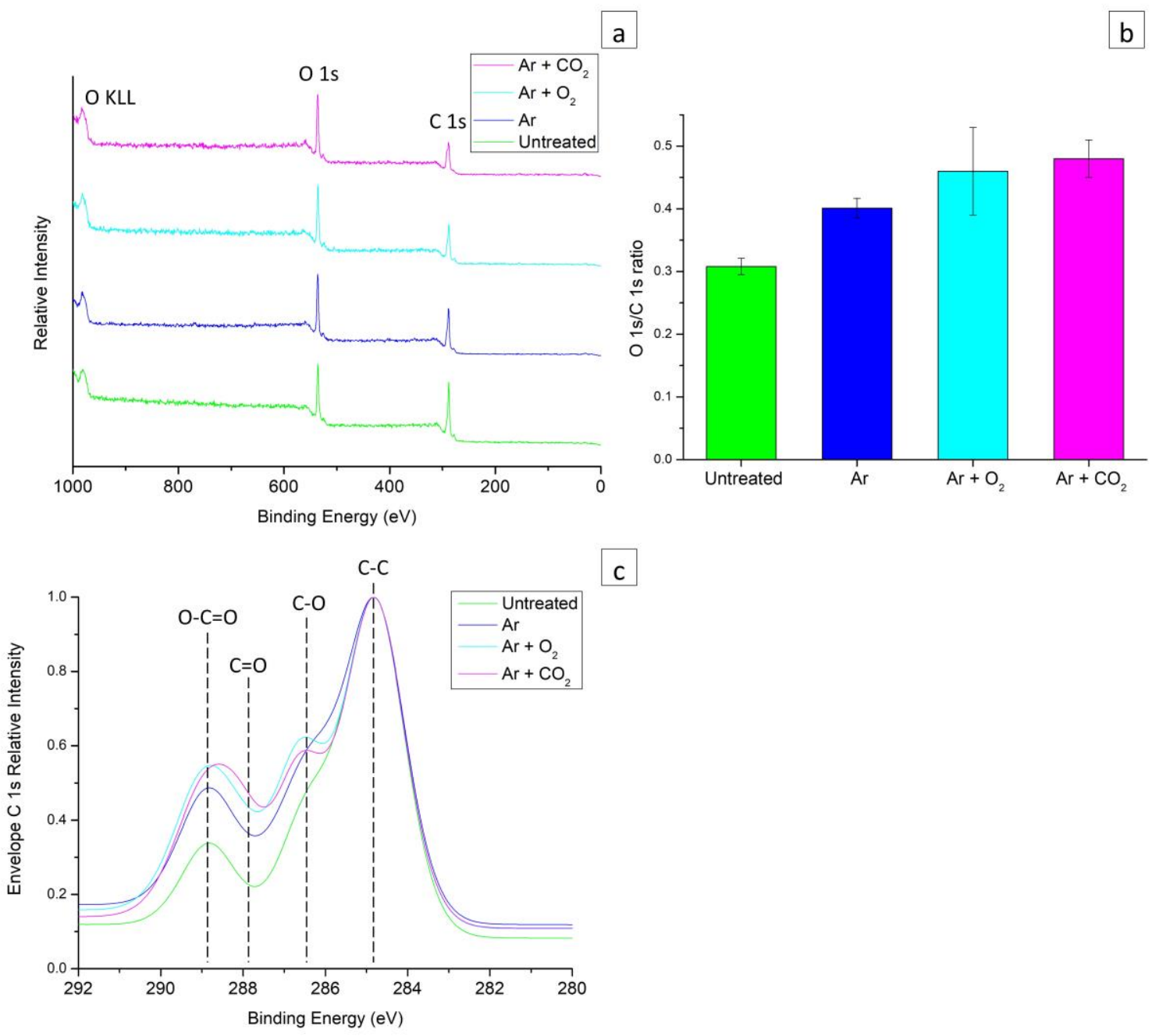

FIGURE 6. Elemental composition (a) and $\mathrm{O} 1 \mathrm{~s} / \mathrm{C} 1 \mathrm{~s}$ ratios (b) determined from XPS survey spectra of untreated and RF torch plasma-treated PET fabric samples with $\mathrm{Ar}, \mathrm{Ar} / \mathrm{O}_{2}$, and $\mathrm{Ar} / \mathrm{CO}_{2}$. In (c), comparison of the $\mathrm{C}$ 1s spectral envelope between the untreated, and the treated PET fabric surfaces. Envelopes were normalized to the C-C peak. Torch operating parameters are: $30 \mathrm{~L} \mathrm{~min}^{-1}$ of Ar as the primary gas (with and without addition of $0.01 \mathrm{~L} \mathrm{~min}^{-1}$ of $\mathrm{O}_{2}$ or $\mathrm{CO}_{2}$ as secondary gas), $60 \mathrm{~W}$ of applied power, a distance of $6 \mathrm{~mm}$ from the samples surface, and a treatment duration of $20 \mathrm{~s}$.

As shown in Figure 7a, by decreasing the gap between the textile samples surface and the head of the torch from 6 to $3 \mathrm{~mm}$, the $t_{\text {wicking }}$ could be decreased further down to a few seconds in the case of pure Ar torch treatment. The WCA measurements on the corresponding model PET samples reported in Figure $7 \mathrm{~b}$ witnessed an increase of wettability in the case of treatment with $\mathrm{Ar} / \mathrm{O}_{2}$ or $\mathrm{Ar} / \mathrm{CO}_{2}$ mixture with a $3 \mathrm{~mm}$ sample-torch distance, which was not evidenced 
by the recorded wicking times. Indeed, the closest the torch is from the sample surface, the more limited are the interaction between the post-discharge and the ambient air. The treatment efficiency is thus enhanced because more of the reactive species of the plasma can interact with the sample surface and potentially modify it. ${ }^{[33]}$
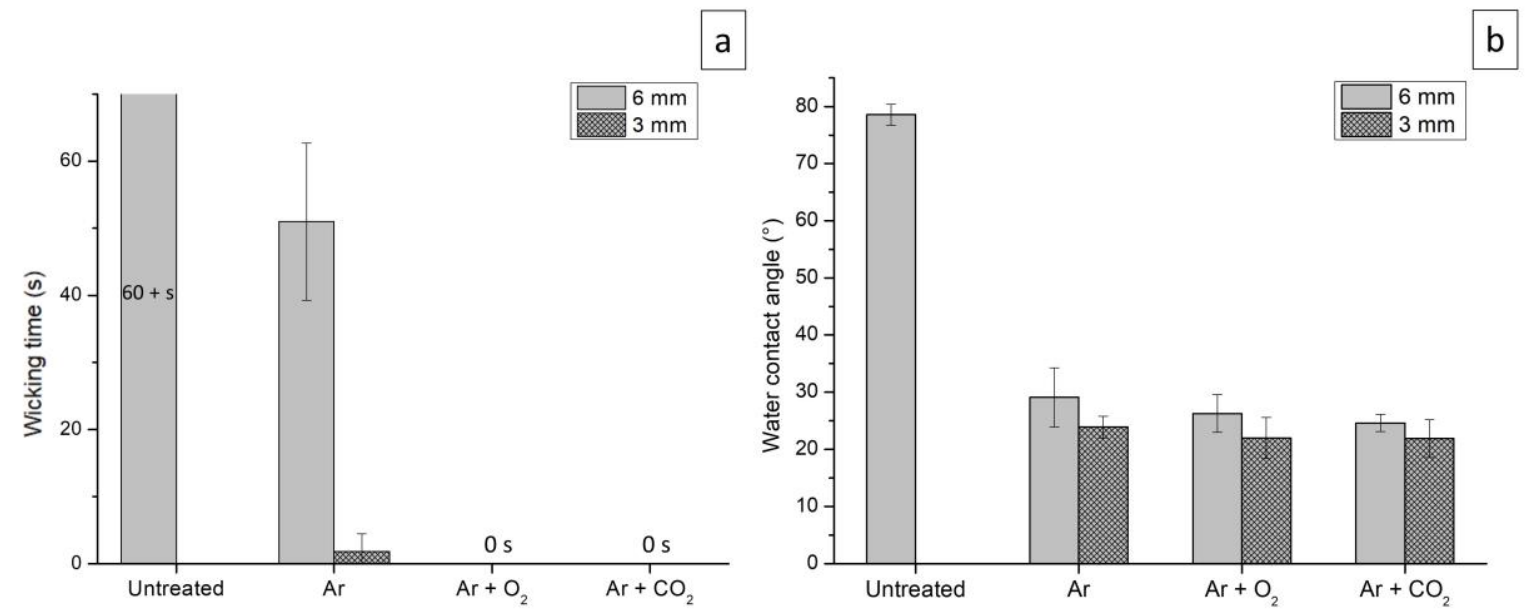

FIGURE 7. Comparison of the wicking time of untreated and RF torch plasma-treated PET fabric (a) and water contact angle of untreated and RF torch plasma-treated model PET foil samples (b) at $6 \mathrm{~mm}$ or $3 \mathrm{~mm}$ from the head of the torch. Torch operating parameters are: $30 \mathrm{~L}$ $\min ^{-1}$ of $\mathrm{Ar}$ as the primary gas (with and without addition of $0.01 \mathrm{~L} \mathrm{~min}^{-1}$ of $\mathrm{O}_{2}$ or $\mathrm{CO}_{2}$ as secondary gas), $60 \mathrm{~W}$ of applied power, and a treatment duration of $10 \mathrm{~s}$.

Noeske et al. and other have shown that the parameters having the strongest effect on the wettability of polymers in the case of APPJ was the distance from the nozzle and the exposure time. ${ }^{[28,34]}$ In our case, we also found that in addition of decreasing the sample-torch distance, the increase of the torch treatment duration also improves water wicking inside PET textile. Figure $8 \mathrm{a}$ reveals that after $20 \mathrm{~s}$ of pure Ar torch treatment at $6 \mathrm{~mm}$ away from the sample surface, instantaneous wicking could be obtained. 

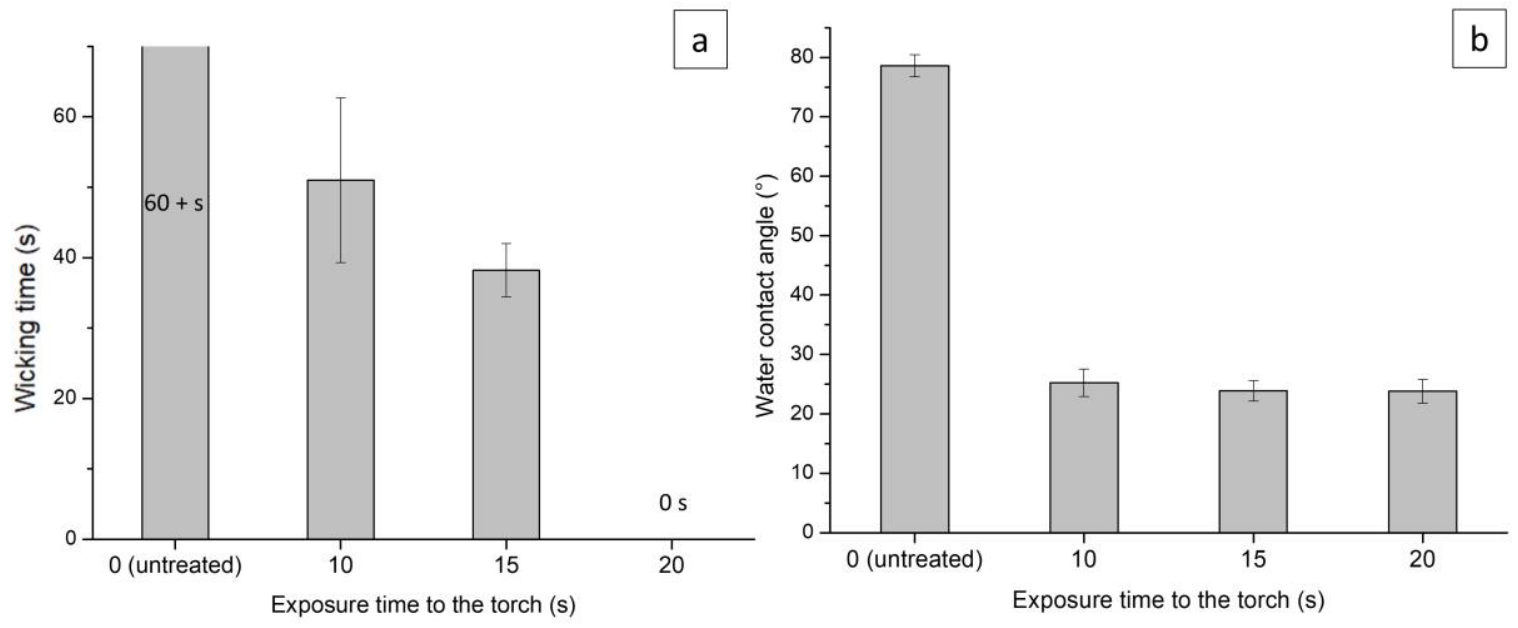

FIGURE 8. Evolution of PET fabric wicking time (a) and water contact angle of model PET foil samples (b) with Ar torch treatment duration. Torch operating parameters are: $30 \mathrm{~L} \mathrm{~min}^{-1}$ of Ar as the primary, $60 \mathrm{~W}$ of applied power, and a distance of $6 \mathrm{~mm}$ from the samples surface.

However, from Figure $8 \mathrm{~b}$ it appears that no significant change of wetting was observed on the model PET foil surface after $10 \mathrm{~s}$ of torch treatment (a plateau is reach at a WCA $25^{\circ}$ ). This could be explained by the fact that in these plasma conditions, the treatment saturation with a maximum level of oxygen incorporation is already reached after $10 \mathrm{~s}$ of treatment on the plain PET material. France et al. evidenced that the latter is generally low for PET compared to other polymer surfaces (PP, LDPE or PS). ${ }^{[35]}$ The treatment saturation of the fabric material is probably reached after longer exposure time to the torch as it is less altered by the plasma than the plain material in the same conditions. The wettability of the fibers could then still be increased after $20 \mathrm{~s}$. The further improvement of wicking with treatment duration could also be attributed to a greater depth of modification, as the reactive species would have more time to diffuse inside the fabric and modify the fibers.

\subsection{PET fabric treated by dielectric barrier discharge (DBD)}


As for the treatments by RF torch, the addition of a secondary gas was investigated in the case of the DBD. Since no significant difference of fabric hydrophilicity was noticed when using $\mathrm{O}_{2}$ or $\mathrm{CO}_{2}$, only $\mathrm{O}_{2}$ was added here.
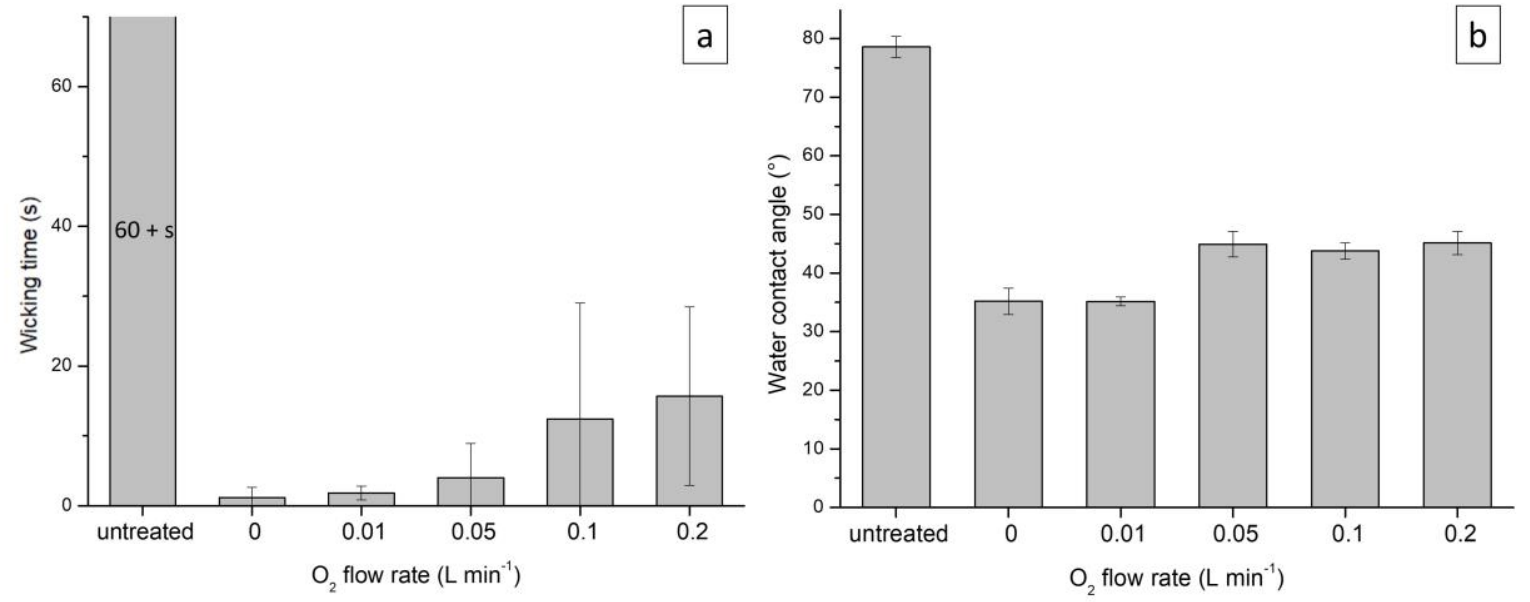

FIGURE 9. Wicking time of untreated and DBD-treated PET fabric samples (a) and WCA measured on untreated and DBD-treated model PET foil samples (b) by Ar DBD with and without addition of $\mathrm{O}_{2}$ to the discharge. DBD operating parameters are: $15 \mathrm{~L} \mathrm{~min}^{-1}$ of Ar the primary gas, $0.01,0.05,0.1$ or $0.2 \mathrm{~L} \mathrm{~min}^{-1}$ of $\mathrm{O}_{2}$ as secondary gas, $60 \mathrm{~W}$ of applied power at $17.14 \mathrm{kHz}, 11 \mathrm{~mm} \mathrm{~s}^{-1}$ displacement speed of the bottom electrode, and a treatment duration of $10 \mathrm{~s}$.

The wicking times recorded on the PET fabrics treated by DBD are reported in Figure 9a. A significant increase of hydrophilicity already appears after $10 \mathrm{~s}$ of DBD treatment with pure Ar ( $t_{\text {wicking }}$ going from $60+\mathrm{s}$ to a tens of $\mathrm{s}$ ). Contrarily to the samples treated by RF torch, $t_{\text {wicking }}$ slightly increased in average with the addition of $\mathrm{O}_{2}$ to the Ar discharge. The WCA measured on the corresponding model PET samples also show a diminution of PET surface wetting with the amount of $\mathrm{O}_{2}$ added (see Figure 9b). Here again, standard deviation of the measurements on a same treated sample were comprised within those of the bare PET surface, showing good surface homogeneity of the treatment.

Fang et al. studied the characteristics of atmospheric pressure DBD generated in $\mathrm{Ar} / \mathrm{O}_{2}$ mixture as a function of oxygen content, and the hydrophilicity of PET films modified by these 
plasmas. ${ }^{[36]}$ They found that when increasing the oxygen amount in mixture from 0 to $3 \%$ with Ar, the consumed discharge power decreases, and the discharge filaments tends to be denser. They also shown that there is an optimal amount of oxygen in the mixture that led to the maximal production of oxygen radicals in the discharge which are mostly responsible for the PET surface modification. The density of these radicals is determined by the competition between the electron impact dissociation of oxygen molecule which generate them, and the electron attachment process of oxygen molecules which consume them. At too high concentration of oxygen in the mixture, the radicals are less numerous because the attachment process is favored over the dissociation of oxygen whereas at lower concentration, oxygen radicals are more abundant because the opposite situation is observed.

In our case, even with the addition of an amount of $\mathrm{O}_{2}$ representing less than $1 \%$ of the total $\mathrm{Ar} / \mathrm{O}_{2}$ mixture $\left(0.01 \mathrm{~L} \mathrm{~min}{ }^{-1}\right)$, the wicking properties of the fabric were not significantly improved, neither was the wetting of the PET model surfaces compared to the treatment with pure Ar. This could be explained by the fact that with the pure Ar DBD discharge, the incorporation of oxygen in the PET surface has already reached a plateau. The addition of oxygen, even at low concentration would then not increase the grafting of oxygen containing functionalities. At higher $\mathrm{O}_{2}$ concentration, the decrease of PET fabric wicking and the decrease of model PET wetting could be explained by a decrease of the amount of radicals because the attachment process of oxygen molecules is favored. As the discharge gets more filamentary with the addition of $\mathrm{O}_{2}$, the resulting treatments are probably less homogenous, which could also explain the less efficient hydrophilization of PET.

Indeed, the XPS analysis of the fabric surface untreated and treated by Ar DBD with and without the addition of $0.1 \mathrm{~L} \mathrm{~min}^{-1}$ of $\mathrm{O}_{2}$ revealed a greater oxygen incorporation in the sample treated with pure Ar in comparison the other samples (see Figure 10a and b). It is also worth noting that no significant difference in the consumed power between pure $\mathrm{Ar}$ and $\mathrm{Ar} / \mathrm{O}_{2}$ mixture 
discharges was found. Lissajous measurements revealed $\sim 56 \mathrm{~W}$ consumed for $60 \mathrm{~W}$ applied in both cases.
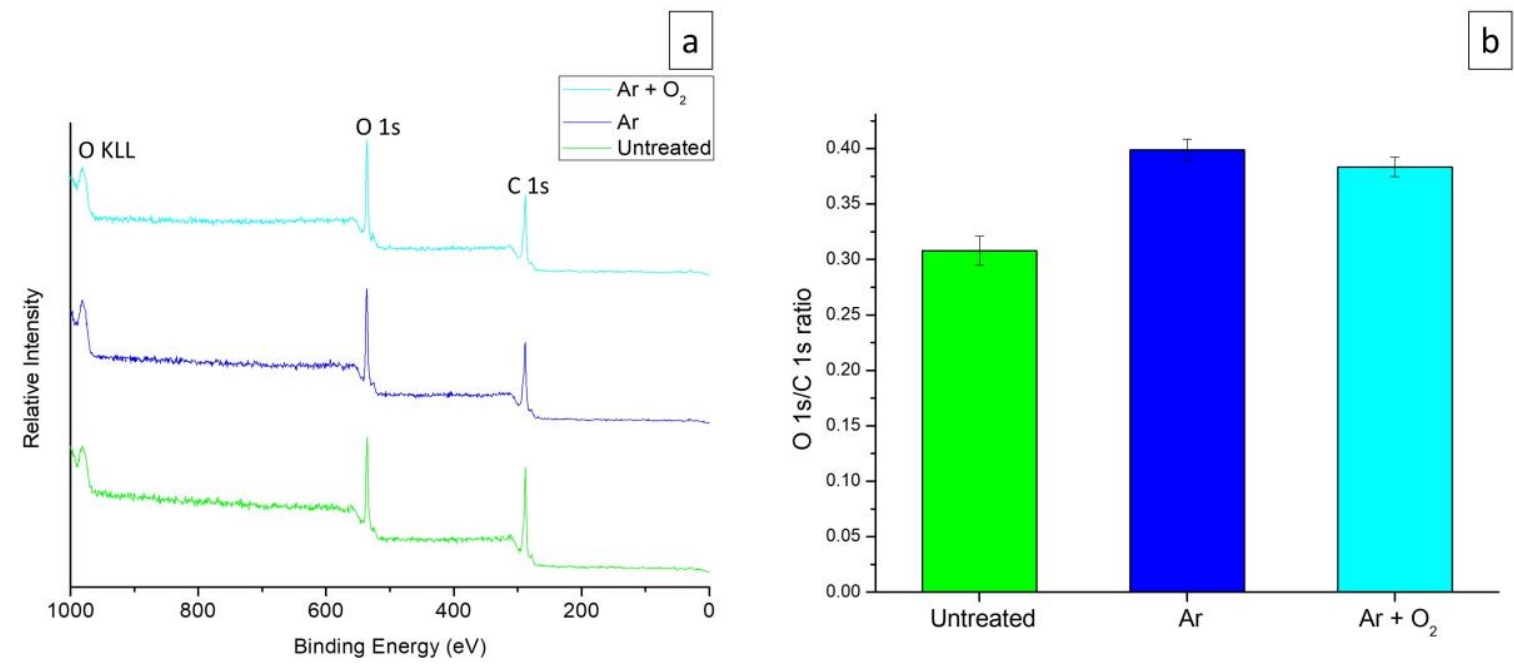

FIGURE 10. Elemental composition (a) and $\mathrm{O} 1 \mathrm{~s} / \mathrm{C} 1 \mathrm{~s}$ ratios (b) determined from XPS survey spectra of PET fabric samples untreated and treated by $\mathrm{Ar}$ and $\mathrm{Ar} / \mathrm{O}_{2}$ DBD. Operating parameters are: $15 \mathrm{~L} \mathrm{~min}^{-1}$ of Ar as the primary gas with and without addition of $0.1 \mathrm{~L} \mathrm{~min}^{-1}$ of $\mathrm{O}_{2}, 60 \mathrm{~W}$ of applied power, $11 \mathrm{~mm} \mathrm{~s}^{-1}$ displacement speed of the bottom electrode, and a treatment duration of $20 \mathrm{~s}$.

As seen in Figure 11, when varying the power applied to the Ar DBD, a significant reduction of $t_{\text {wicking }}$ is already observed at $40 \mathrm{~W}$ and decreases furthermore at $60 \mathrm{~W}$ and $80 \mathrm{~W}$. As a comparison, the WCA measured on the model PET (see Figure 11) also decrease with the applied power. This tendency is probably related to the increasing number of electrons in the discharge with the applied power, which generate more reactive species emphasizing the modification of PET surface. It is worth noting that, due to the difference of plasma treatment efficiency between the two materials, the treatment saturation might be already reached at 40 W for the plain PET surface but not for the fibers surface. The further increase of power thus induces a smaller difference of wettability for the model than for the fabric surface. 

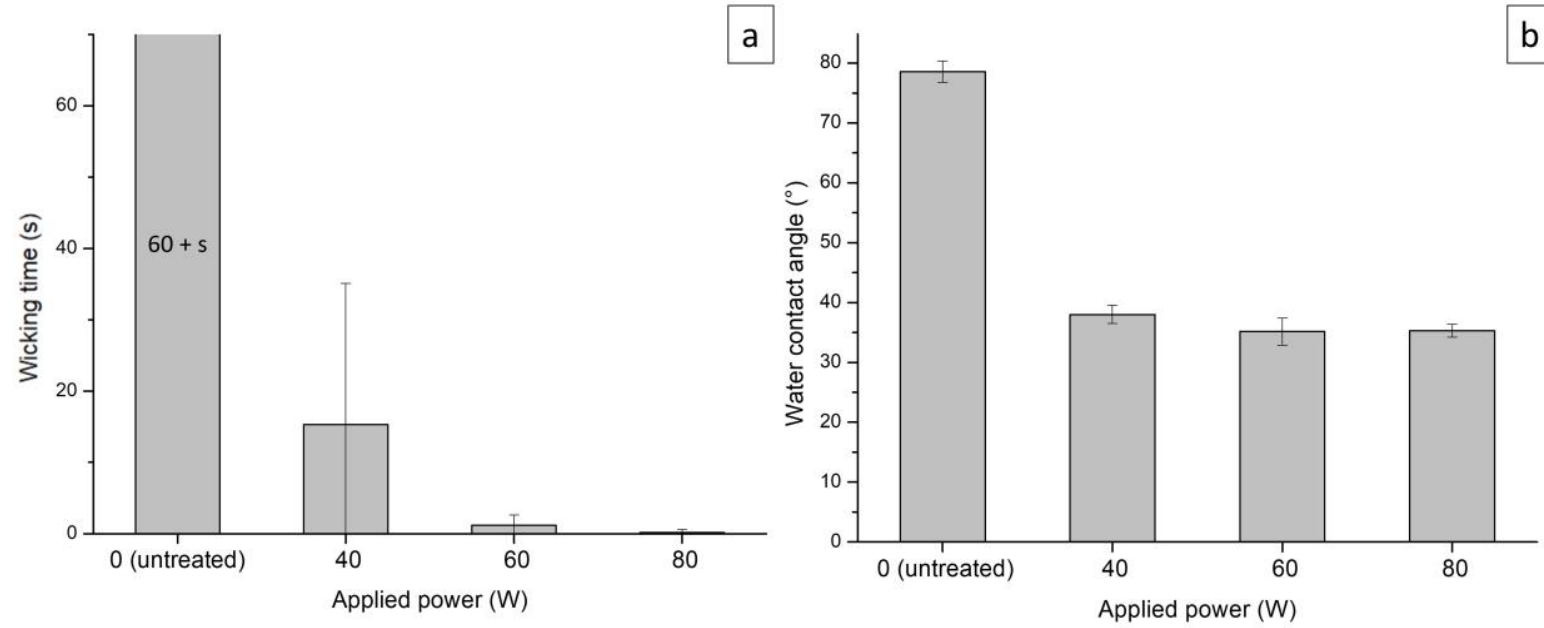

FIGURE 11. Evolution of PET fabric wicking time (a) and of water contact angle measured on model PET foil sample (b) with applied power. DBD operating parameters are: $15 \mathrm{~L} \mathrm{~min}^{-1}$ of Ar, frequency of $17.14 \mathrm{kHz}, 11 \mathrm{~mm} \mathrm{~s}^{-1}$ displacement speed of the bottom electrode, and a treatment duration of $10 \mathrm{~s}$.

The increase of exposure time to the DBD had the same effect on the PET textile wicking properties than in the case of RF torch. Results of the absorbency test reported in Figure $11 \mathrm{~b}$ show that after $10 \mathrm{~s}$ of DBD treatment, the absorption of water is significantly faster (around few s) and become instantaneous after $30 \mathrm{~s}$ of treatment.

WCA measurements on the model PET reported in Figure 12, indicate that PET wettability is improved with treatment duration, however the values of WCA after $10 \mathrm{~s}$ of treatment are a bit higher than in the case of the treatments with RF torch positioned at $3 \mathrm{~mm}$ away from the sample ( $\sim 35^{\circ}$ for the DBD versus $\sim 25^{\circ}$ for the torch). Even after $75 \mathrm{~s}$ second of DBD treatment, the WCA did not reach the same WCA plateau $\left(\sim 25^{\circ}\right)$ than in the case of the torch treatment. This might be explained by local heating of the torch device, transferring heat to the postdischarge. Polymer surfaces being sensitive to temperature, the heating of the surface with the torch could accentuate the surface modifications during the plasma treatments. 

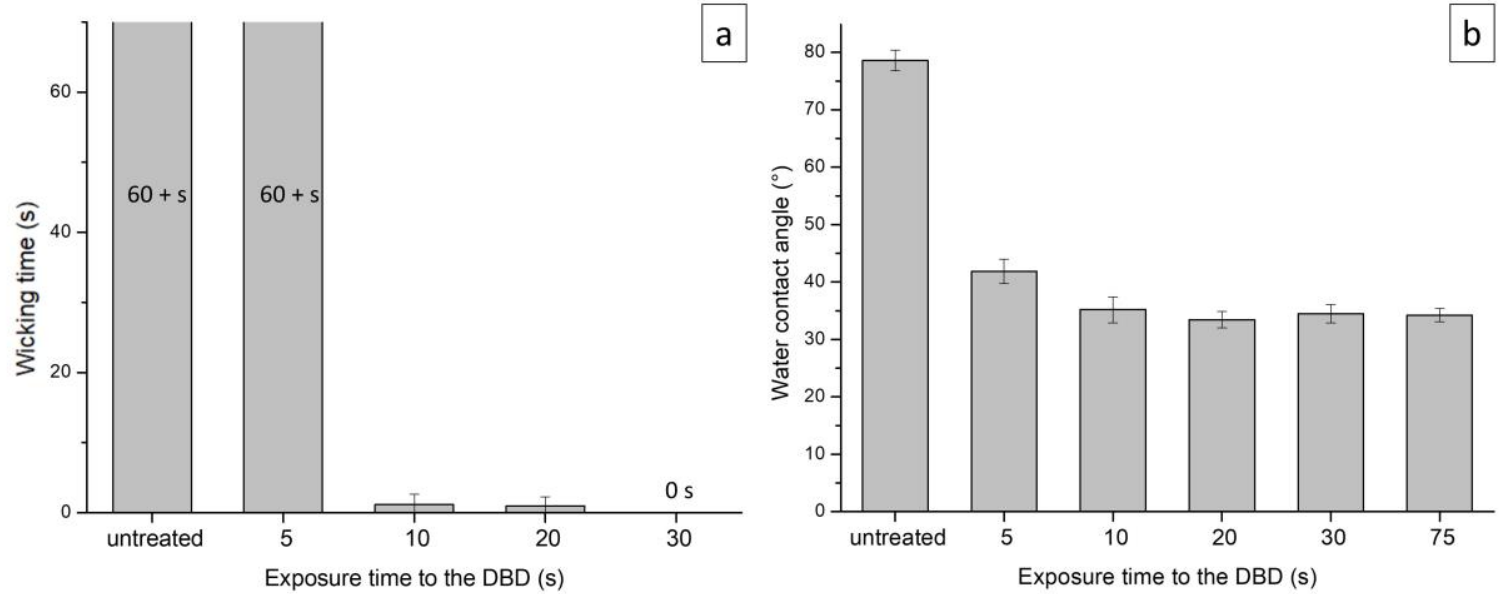

FIGURE 12. Evolution of PET fabric wicking time (a) and WCA measured on model PET foil samples (b) with Ar DBD treatment duration. DBD operating parameters are: $15 \mathrm{~L} \mathrm{~min}^{-1}$ of $\mathrm{Ar}$, $60 \mathrm{~W}$ of applied power at $17.14 \mathrm{kHz}, 11 \mathrm{~mm} \mathrm{~s}^{-1}$ displacement speed of the bottom electrode.

\section{CONCLUSION}

A DBD and an RF plasma torch both operating under Ar at atmospheric pressure where used separately to improve the hydrophilicity of PET textile. For each device, different parameters such as the addition of $\mathrm{O}_{2}$ or $\mathrm{CO}_{2}$ to the discharge, the exposure time, the applied power, or the distance between the torch and the sample were varied. The evolution of the wicking properties of the fabric with the different plasma treatments was assessed by a novel wicking test developed in this study. Water contact angles were measured in parallel on a plain PET surface submitted to the same treatment as a comparison, and showed that surface wettability alone, although correlated, is not a sufficient criterion to correctly predict the wicking properties. Finally, it was found that, whereas the untreated PET fabric is highly hydrophobic, both remote and direct plasma treatment can generate an almost instantaneous wicking of water inside the textile fibers within $10 \mathrm{~s}$ of pure Ar treatments. XPS analysis of the treated samples allowed to partially relate this increase of hydrophilicity to the incorporation of oxygen to the fibers surface 
in the form of oxygen containing polar groups. Potential generation of roughness on the fibers surface due to plasma etching can also have play a role in this matter.

In the case of the torch, the distance from the head to the sample revealed to be a key parameter, with possibly increasing amount of reactive species reaching the sample surface when decreasing the distance. The wicking time of PET fabric could be further reduced with the addition of $\mathrm{O}_{2}$ or $\mathrm{CO}_{2}$ to the discharge. In the case of $\mathrm{DBD}$, the addition of $\mathrm{O}_{2}$ to the discharge had the opposite effect on the fabric wicking. The later could be diminished by increasing the power. In both cases, the increase of exposure time emphasized the modification of the fibers surface leading to better wicking properties.

\section{ACKNOWLEDGMENTS}

This work was funded by the SmartHyCAR project (European M-EraNet call $2016-\mathrm{n}^{\circ}$ 1610176, and Walloon Region, Belgium) and by the Fund for Scientific Research (F.R.S.FNRS, Belgium). The authors also thank David Petitjean for his technical help on the research experiments.

\section{AUTHOR CONTRIBUTIONS}

A.D. wrote the paper and performed most of the investigation and experiments. She was also involved in conceptualization. R.I., C.S. P.L, F.R were involved in project management and conceptualization, reviewing editing. F.R. did the final editing of the manuscript (with A.D.) and is the principal investigator of this research.

\section{CONFLICT OF INTEREST}

The authors declare no financial or commercial conflict of interest.

\section{DATA AVAILABILITY STATEMENT}


The data that support the findings of this study are available from the corresponding author upon reasonable request.

\section{REFERENCES}

[1] Zille, A.; Oliveira, F. R.; Souto, A. P. Plasma Treatment in Textile Industry: Plasma Treatment in Textile Industry. Plasma Process. Polym. 2015, 12 (2), 98-131.

[2] Behary, N.; Kerkeni, A.; Perwuelz, A.; Chihib, N.-E.; Dhulster, P. Bioactivation of PET Woven Fabrics Using Alginate Biopolymer and the Bacteriocin Nisin. Text. Res. J. 2013, 83 (11), 1120-1129.

[3] Gotoh, K.; Yoshitaka, S. Improvement of Soil Release from Polyester Fabric with Atmospheric Pressure Plasma Jet. Text. Res. J. 2013, 83 (15), 1606-1614.

[4] Takke, V.; Behary, N.; Perwuelz, A.; Campagne, C. Surface and Adhesion Properties of Poly(Ethylene Glycol) on Polyester(Polyethylene Terephthalate) Fabric Surface: Effect of Air-Atmospheric Plasma Treatment. J. Appl. Polym. Sci. 2011, 122 (4), 2621-2629.

[5] C. M. Pastore, P. Kiekens, Surface Characteristics of Fibers and Textiles, Surfactant science series, M. Dekker, NY, USA 2001.

[6] Kan, C. W.; Yuen, C. W. M. Static Properties and Moisture Content Properties of Polyester Fabrics Modified by Plasma Treatment and Chemical Finishing. Nucl. Instrum. Methods Phys. Res. Sect. B Beam Interact. Mater. At. 2008, 266 (1), 127-132.

[7] Kowalski, J. M.; Wróblewska, M. Premises for Practical Evaluation of the Anti Electrostatic Properties of Protective Garments. Fibres Text. East. Eur. 2006, Nr 5 (59).

[8] Li, S.; Huang, J.; Chen, Z.; Chen, G.; Lai, Y. A Review on Special Wettability Textiles: Theoretical Models, Fabrication Technologies and Multifunctional Applications. $J$. Mater. Chem. A 2016, 5 (1), 31-55.

[9] Mikhailova, O. V.; Pavlov, N. N.; Barantsev, V. M.; Degtyarev, S. V. Increasing the Hydrophilicity of Polyester Fibres and Fabrics by Treatment with Solutions of Metal Salts. Fibre Chem. 2008, 40 (2), 107-109.

[10] Luo, S.; Ooij, W. J. V. Surface Modification of Textile Fibers for Improvement of Adhesion to Polymeric Matrices: A Review. J. Adhes. Sci. Technol. 2002, 16 (13), 17151735.

[11] Zeronian, S. H.; Collins B.S., M. J. Surface Modification of Polyester by Alkaline Treatments. Text. Prog. 1989, 20 (2), 1-26. 
[12] Pasquet, V.; Behary, N.; Perwuelz, A. Environmental Impacts of

Chemical/Ecotechnological/Biotechnological Hydrophilisation of Polyester Fabrics. J. Clean. Prod. 2014, 65, 551-560.

[13] Ferrero, F. Wettability Measurements on Plasma Treated Synthetic Fabrics by Capillary Rise Method. Polym. Test. 2003, 22 (5), 571-578.

[14] Negulescu, I. I.; Despa, S.; Chen, J.; Collier, B. J.; Despa, M.; Denes, A.; Sarmadi, M.; Denes, F. S. Characterizing Polyester Fabrics Treated in Electrical Discharges of RadioFrequency Plasma: Text. Res. J. 2016.

[15] Wakida, T.; Kawamura, H.; Han, L.; Kim, K. H.; Goto, T.; Takagishi, T. Changes in Surface Properties of Poly(Ethylene Terephtalate) Treated with Low Temperature Plasma: Effect of Pretreatment with Dimethylformamide. 1986, 42, 5.

[16] Morent, R.; De Geyter, N.; Verschuren, J.; De Clerck, K.; Kiekens, P.; Leys, C. NonThermal Plasma Treatment of Textiles. Surf. Coat. Technol. 2008, 202 (14), 3427-3449.

[17] Carnazza, S.; Satriano, C.; Guglielmino, S.; Marletta, G. Fast Exopolysaccharide Secretion of Pseudomonas Aeruginosa on Polar Polymer Surfaces. J. Colloid Interface Sci. 2005, 289 (2), 386-393.

[18] Leroux, F.; Perwuelz, A.; Campagne, C.; Behary, N. Atmospheric Air-Plasma Treatments of Polyester Textile Structures. J. Adhes. Sci. Technol. 2006, 20 (9), 939-957. [19] Takke, V.; Behary, N.; Perwuelz, A.; Campagne, C. Studies on the Atmospheric AirPlasma Treatment of PET (Polyethylene Terephtalate) Woven Fabrics: Effect of Process Parameters and of Aging. J. Appl. Polym. Sci. 2009, 114 (1), 348-357.

[20] Kan, C. W.; Yuen, C. W. M. Effect of Atmospheric Pressure Plasma Treatment on Wettability and Dryability of Synthetic Textile Fibres. Surf. Coat. Technol. 2013, 228, S607S610.

[21] Kakaroglou, A.; Nisol, B.; Baert, K.; De Graeve, I.; Reniers, F.; Van Assche, G.; Terryn, H. Evaluation of the Yasuda Parameter for the Atmospheric Plasma Deposition of Allyl Methacrylate. RSC Adv. 2015, 5 (35), 27449-27457.

[22] Nisol, B.; Ghesquière, J.; Reniers, F. Easy Synthesis of Ageing-Resistant Coatings with Tunable Wettability by Atmospheric Pressure Plasma. Plasma Chem. Plasma Process. 2016, 36 (5), 1239-1252.

[23] American Association of Textile Chemists and Colorists, AATCC Technical Manual, Vol. 85, Research Triangle Park, NY, USA 2010.

[24] Kissa, E. Wetting and Wicking. Text. Res. J. 1996, 66 (10), 660-668. 
[25] Memariyan, F.; Ekhtiyari, E. Study On Wicking Measurement In Thin Layer Textiles By Processing Digital Images. IJE Trans. Basics 2010, 23 (1), 101-108.

[26] Morent, R.; De Geyter, N.; Leys, C.; Vansteenkiste, E.; De Bock, J.; Philips, W. Measuring the Wicking Behavior of Textiles by the Combination of a Horizontal Wicking Experiment and Image Processing. Rev. Sci. Instrum. 2006, 77 (9), 093502.

[27] Harnett, P. R.; Mehta, P. N. A Survey and Comparison of Laboratory Test Methods for Measuring Wicking. Text. Res. J. 1984, 54 (7), 471-478.

[28] Onyshchenko, I.; Yu Nikiforov, A.; De Geyter, N.; Morent, R. Local Analysis of Pet Surface Functionalization by an Atmospheric Pressure Plasma Jet: Local Analysis of Pet Surface Functionalization.... Plasma Process. Polym. 2015, 12 (5), 466-476.

[29] Huang, C.; Chang, Y.-C.; Wu, S.-Y. Contact Angle Analysis of Low-Temperature Cyclonic Atmospheric Pressure Plasma Modified Polyethylene Terephthalate. Thin Solid Films 2010, 518 (13), 3575-3580.

[30] Fang, Z.; Yang, J.; Liu, Y.; Shao, T.; Zhang, C. Surface Treatment of Polyethylene Terephthalate to Improving Hydrophilicity Using Atmospheric Pressure Plasma Jet. IEEE Trans. Plasma Sci. 2013, 41 (6), 1627-1634.

[31] Cheng, C.; Liye, Z.; Zhan, R.-J. Surface Modification of Polymer Fibre by the New Atmospheric Pressure Cold Plasma Jet. Surf. Coat. Technol. 2006, 200 (24), 6659-6665.

[32] Tkavc, T.; Petrinič, I.; Luxbacher, T.; Vesel, A.; Ristić, T.; Zemljič, L. F. Influence of $\mathrm{O}_{2}$ and $\mathrm{CO}_{2}$ Plasma Treatment on the Deposition of Chitosan onto Polyethylene Terephthalate (PET) Surfaces. Int. J. Adhes. Adhes. 2014, 48, 168-176.

[33] Dufour, T.; Minnebo, J.; Abou Rich, S.; Neyts, E. C.; Bogaerts, A.; Reniers, F. Understanding Polyethylene Surface Functionalization by an Atmospheric $\mathrm{He} / \mathrm{O}_{2}$ Plasma through Combined Experiments and Simulations. J. Phys. Appl. Phys. 2014, 47 (22), 224007. [34] Noeske, M.; Degenhardt, J.; Strudthoff, S.; Lommatzsch, U. Plasma Jet Treatment of Five Polymers at Atmospheric Pressure: Surface Modifications and the Relevance for Adhesion. Int. J. Adhes. Adhes. 2004, 24 (2), 171-177.

[35] France, R. M.; Short, R. D. Plasma Treatment of Polymers Effects of Energy Transfer from an Argon Plasma on the Surface Chemistry Of Poly(Styrene), Low Density Poly(Ethylene), Poly(Propylene)and Poly(Ethylene Terephthalate). J. Chem. Soc. Faraday Trans. 1997, 93 (17), 3173-3178.

[36] Fang, Z.; Shao, T.; Wang, R.; Yang, J.; Zhang, C. Influences of Oxygen Content on Characteristics of Atmospheric Pressure Dielectric Barrier Discharge in Argon/Oxygen Mixtures. Eur. Phys. J. D 2016, 70 (4). 


\section{Graphical Abstract}

DBD and remote RF plasma torch are used and compared to modulate the wicking and wetting properties of polyethylene terephthalate fabric. It is found that both devices allow an efficient and easy control of the fibers hydrophilization, although some shared parameters do not have the same effect on the fabric surface modification.

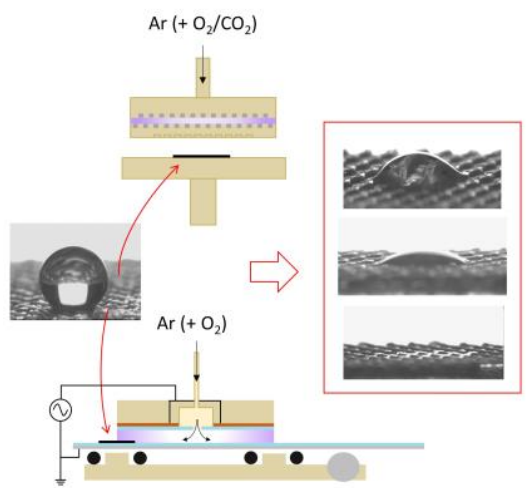

